\title{
Neurophysiologic Profiling of At-Risk Low and Very Low Birth-Weight Infants Using Magnetic Resonance Imaging
}

Ying $\mathrm{Qi}^{1}$ and Jingni $\mathrm{He}^{2 *}$

${ }^{1}$ Department of Radiology, Shengjing Hospital of China Medical University, Shenyang, China, ${ }^{2}$ Department of Surgery, Shengjing Hospital of China Medical University, Shenyang, China

Low birth-weight (LBW) and very low birth-weight (VLBW) newborns have increased risks of brain injuries, growth failure, motor difficulties, developmental coordination disorders or delay, and adult-onset vascular diseases. However, relatively little is known of the neurobiologic underpinnings. To clarify the pathophysiologic vulnerabilities of such neonates, we applied several advanced techniques for assessing brain physiology, namely T2-relaxation-under-spin-tagging (TRUST) magnetic resonance imaging (MRI)

OPEN ACCESS

Edited by:

Charles Evans Wood,

University of Florida, United States

Reviewed by:

Bradley Keller,

Heart Institute, Cincinnati Children's Hospital Medical Center,

United States

Robert Dietz,

University of Colorado, United States

Ravi Goyal,

University of Arizona, United States

${ }^{*}$ Correspondence:

Jingni $\mathrm{He}$

jingnihe@foxmail.com;

hejn@sj-hospital.org

Specialty section:

This article was submitted to

Developmental Physiology,

a section of the journal

Frontiers in Physiology

Received: 07 December 2020

Accepted: 02 March 2021

Published: 23 March 2021

Citation:

Qi Y and He J (2021)

Neurophysiologic Profiling of At-Risk

Low and Very Low Birth-Weight

Infants Using Magnetic Resonance

Imaging. Front. Physiol. 12:638868.

doi: 10.3389/fphys.2021.638868 and phase-contrast (PC) MRI. This enabled quantification of oxygen extraction fraction (OEF), global cerebral blood flow (CBF), and cerebral metabolic rate of oxygen $\left(\mathrm{CMRO}_{2}\right)$. A total of 50 neonates (LBW-VLBW, 41; term controls, 9) participated in this study. LBWVLBW neonates were further stratified as those with (LBW-VLBW-a, 24) and without (LBW-VLBW-n, 17) structural MRI (sMRI) abnormalities. TRUST and PC MRI studies were undertaken to determine $\mathrm{OEF}, \mathrm{CBF}$, and $\mathrm{CMRO}_{2}$. Ultimately, $\mathrm{CMRO}_{2}$ proved significantly lower $(p=0.01)$ in LBW-VLBW (vs term) neonates, both LBW-VLBW-a and LBW-VLBW-n subsets showing significantly greater physiologic deficits than term controls ( $p=0.03$ and $p=0.04$, respectively). $\mathrm{CMRO}_{2}$ and CBF in LBW-VLBW-a and LBW-VLBW-n subsets did not differ significantly $(\rho>0.05)$, although OEF showed a tendency to diverge $(p=0.15)$. However, OEF values in the LBW-VLBW-n subset differed significantly from those of term controls $(p=0.02)$. Compared with brain volume or body weight, these physiologic parameters yield higher area-under-the-curve (AUC) values for distinguishing neonates of the LBW-VLBW-a subset. The latter displayed distinct cerebral metabolic and hemodynamic, whereas changes were marginal in the LBW-VLBW-n subset (i.e., higher OEF and lower CBF and $\mathrm{CMRO}_{2}$ ) by comparison. Physiologic imaging may therefore be useful in identifying LBW-VLBW newborns at high risk of irreversible brain damage.

Keywords: low birth weight (LBW), very low birth weight (VLBW), PC MRI, TRUST MRI, $\mathrm{CMRO}_{2}, \mathrm{CBF}$, OEF

\section{INTRODUCTION}

Preterm newborns of low birth weight (LBW, $\leq 2,500 \mathrm{~g}$ ) or very low birth weight (VLBW, $\leq 1,500 \mathrm{~g}$ ) present a substantial public health problem. In 2015, the worldwide prevalence was $14.6 \%$, with $91 \%$ confined to low- and middle-income countries [primarily Southern Asia (24\%) and sub-Saharan Africa (48\%)]. More than $80 \%$ of perinatal deaths occur in LBW neonates (Blencowe et al., 2019). 
Although most LBW and VLBW preterm infants show catchup gains in height and weight, they are still at increased risk of brain injuries (Martinussen et al., 2005), growth failure (Tchamo et al., 2016), motor difficulties, developmental coordination disorders or delay (Burns et al., 2009), adult-onset vascular diseases (Blencowe et al., 2013; Christian et al., 2013), and type 2 diabetes (Barker, 2003). It also appears that catch-up or postnatal accelerated growth in LBW and VLBW neonates may adversely affect cognitive function (Estourgie-van Burk et al., 2009). Consequently, better understanding of neonatal brain functions, particularly cerebral oxygen metabolism and hemodynamics, may provide important pathophysiologic insights in this setting.

Because neonatal brain sizes are small and highly vulnerable in terms of motion and scanning times, physiologic and functional brain imaging is especially challenging. ${ }^{133}$ Xenon clearance (Colditz et al., 1988), computed tomography (CT; Dani et al., 2012), positron emission tomography (PET; Wright et al., 2016), and near-infrared spectroscopy (NIRS; Kusaka et al., 2014; Hashem et al., 2020) are common methods used to measure metabolism and cerebral blood flow (CBF) in adults. Unfortunately, the above involve radiation exposure, present difficulties when imaging deep brain tissues, or require exogenous tracers. As a result, their use in neonatal brain imaging is limited.

Recent advances in magnetic resonance imaging (MRI) technologies have allowed noninvasive and quantitative measurements of critical neurophysiologic parameters, without need of contrast agents. The oxygen extraction fraction (OEF) of the brain is assessable using T2-relaxation-under-spin-tagging (TRUST) MRI technique (Liu et al., 2014), and global CBF may be measured using quantitative flow phase-contrast (PC) MRI. $\mathrm{OEF}$ and $\mathrm{CBF}$ may then be combined to determine the global cerebral metabolic rate of oxygen $\left(\mathrm{CMRO}_{2}\right.$; Liu et al., 2014). Importantly, these physiologic measures are fully obtained in $<5$ min, making them particularly suitable for neonatal testing (Qi et al., 2018; Shetty et al., 2019).

Arterial spin labeling (ASL) is another valuable means of perfusion MRI for this purpose. However, its signal-to-noise ratio (SNR) tends to be lower, the scan times lengthier, and there is a potential for confounding factors (i.e., bolus arrival time). In an earlier effort, infants with hypoxic ischemic encephalopathy (HIE) showed lower $\mathrm{CBF}$ and $\mathrm{CMRO}_{2}$ using T2 prepared tissue relaxation inversion recovery (T2-TRIR) pulse sequences and ASL (De Vis et al., 2014). Newborns with severe HIE have also registered lower CBF and extracted less oxygen than those with moderate HIE using ASL and NIRS, a strong correlation found between $\mathrm{CMRO}_{2}$ and $\mathrm{CBF}$ in asphyxiated newborns with severe HIE $(r=0.88)$ (Wintermark et al., 2014). Our previous look at newborns with white matter damage indicated lower oxygen consumption and CBF using PC MRI and TRUST MRI (Qi et al., 2018). Tortora has similarly reported on CBF (via ASL) in preterm neonates (birth weights, 1,317-2,250 g; postmenstrual ages, 36-39 weeks) with low-grade germinal matrix-intraventricular hemorrhage (GMH-IVH), finding significantly lower rates than in preterm neonates (birth weights, 1,160-1,680 g; postmenstrual ages, 3841 weeks) without MRI abnormalities (Tortora et al., 2020). There have been few perinatal studies of cerebral oxygen metabolism and hemodynamics in LBW and VLBW preterm infants, especially at postmenstrual ages before term and taking structural abnormalities into account.

In the present study, we used TRUST MRI and PC MRI to determine $\mathrm{OEF}, \mathrm{CBF}$, and $\mathrm{CMRO}_{2}$ in a mixed group of LBW and VLBW newborns, comparing outcomes with those of term neonates.

\section{MATERIALS AND METHODS}

\section{Study Population}

Our investigational protocol received approval from the Ethics Committee at Shengjing Hospital of China Medical University. Between June 2016 and December 2018, a total of 50 newborns accrued for study. The structural MRI pulse sequences performed included axial and sagittal T1-weighted imaging (TIWI), axial T2-weighted imaging (T2WI), and diffusion-weighted imaging (DWI). Congenital malformations, severe infections, or unusable MRI studies were grounds for exclusion. Subjects qualified as LBW-VLBW $(n=41)$ at birth weights $>1,000 \mathrm{~g}$ but $<2,500$ g. Term neonates serving as controls $(n=9)$ had birth weights $\geq 2,500 \mathrm{~g}$, were $\geq 37$ weeks at birth, and showed no sMRI abnormalities. Population characteristics and results of blood gas analysis were listed in Table 1. All LBW-VLBW infants were preterm, grouped as those with (LBW-VLBWa) or without (LBW-VLBW-n) structural MRI abnormalities. Doing so approximates the needs of pediatricians. During perinatal periods, there are often no neurobehavioral differences in preterm LBW and full-term babies (Silva et al., 2018). MRI is frequently used to determine neonatal structural brain damage, assessing type and extent of injury, gray and white matter volumes, and prognostic status. These studies aid in diagnostic accuracy, helping pediatricians formulate helpful and safe treatments and develop long-term followup plans.

Conventional MR images (including T1WI, T2WI and DWI) obtained from all infants (LBW-VLBW and term) were viewed as Picture Archiving and Communication Systems (PACS) files by two neuroradiologists (YQ and XYS) with 10 years of experience, each blinded to group data. They independently scored MRI abnormalities for each infant, using a method similar to one already described (Woodward et al., 2006) that focuses on six components: gray and white matter signal intensity on T1WI and T2WI, volume of periventricular white matter, presence of blood product deposition or cysts, ventricular dilation, abnormalities on DWI, and corpus callosum thickness. Each aspect was scored (1-4) accordingly (normal, 1; mild, 2; moderate, 3; severe, 4). MRI scores were the sum of the six categorical scores, averaged. Normal brains would thus receive average scores of 6 , higher figures indicating abnormalities of commensurate severity.

\section{General MRI Protocol}

A 3T MRI system equipped with a phased-array head coil (Intera Achieva; Philips Healthcare, Best, Netherlands) was used for all MR scans. Prior to imaging procedures, a pediatrician sedated infants through nasal feedings of chloral hydrate $(50 \mathrm{mg} / \mathrm{kg})$. This 
TABLE 1 | Clinical characteristics of low birth-weight/very low birth-weight (LBW-VLBW) and term neonates.

\begin{tabular}{|c|c|c|c|c|c|}
\hline & & LBW-VLBW $(n=41)$ & Term $(n=9)$ & $z / \chi^{2}$ & $p$ value \\
\hline \multirow[t]{4}{*}{ Characteristics } & Males & $27(65.9)$ & $7(77.8)$ & 6.5 & $0.011^{\star}$ \\
\hline & Birth weight, $g$ & $1709.2 \pm 404.5$ & $3461.1 \pm 755.7$ & -9.9 & $<0.001^{*}$ \\
\hline & Birth age, weeks & $32.1 \pm 2.4$ & $39.0 \pm 1.0$ & -13.7 & $<0.001^{*}$ \\
\hline & Scan age, weeks & $35.3 \pm 2.3$ & $40.8 \pm 2.1$ & -6.5 & $<0.001^{*}$ \\
\hline \multirow[t]{6}{*}{ Blood gas analysis } & Total tested & $36(87.8)$ & 8 (88.9) & & \\
\hline & $\mathrm{pH}$ & $7.4 \pm 0.06$ & $7.4 \pm 0.06$ & 1.60 & 0.11 \\
\hline & $\mathrm{PCO}_{2}, \mathrm{mmHg}$ & $43.2 \pm 7.3$ & $40.8 \pm 6.2$ & 1.0 & 0.34 \\
\hline & $\mathrm{PaO}_{2}, \mathrm{mmHg}$ & $87.1 \pm 6.8$ & $90.4 \pm 2.0$ & -1.6 & 0.12 \\
\hline & $\mathrm{SaO}_{2}, \%$ & $94.8 \pm 6.3$ & $96.8 \pm 1.5$ & -0.1 & 0.92 \\
\hline & Glucose, $\mathrm{mmol} / \mathrm{L}$ & $4.6 \pm 1.2$ & $4.6 \pm 0.7$ & 0.1 & 0.91 \\
\hline
\end{tabular}

Data expressed as $n$ (\% total) or mean \pm standard deviation.

${ }^{*} P<0.05$.

$\mathrm{PCO}_{2}$, partial pressure of carbon dioxide; $\mathrm{PaO}_{2}$, partial pressure of oxygen; $\mathrm{SaO}_{2}$, oxygen saturation.

is standard clinical practice at our institution. All newborns were well fed, visually monitored, and hearing protected during scans.

Axial T1-weighted spin-echo images were acquired at the following settings: repetition time/echo time (TR/TE), $200 \mathrm{~ms} / 2.3 \mathrm{~ms}$; section thickness, $5 \mathrm{~mm}$; field of view (FOV), $180 \mathrm{~mm} \times 150 \mathrm{~mm} \times 89 \mathrm{~mm}$; matrix size, $224 \times 162$; and scan time, $34.4 \mathrm{~s}$. For sagittal T1-weighted spin-echo images, the following settings were used: TR/TE, $250 \mathrm{~ms} / 2.3 \mathrm{~ms}$; section thickness, $5 \mathrm{~mm}$; FOV, $230 \mathrm{~mm} \times 230 \mathrm{~mm} \times 107 \mathrm{~mm}$; matrix size, $256 \times 250$; and scan time, 33.0 s. Axial T2WI used the following settings: TR/TE, $5,000 \mathrm{~ms} / 80 \mathrm{~ms}$; section thickness, $5 \mathrm{~mm}$; FOV, $180 \mathrm{~mm} \times 150 \mathrm{~mm} \times 90 \mathrm{~mm}$; matrix size, $112 \times 112$; and scan time, $40.9 \mathrm{~s}$. Axial echo-planar imaging (EPI) DWI was performed as follows: TR/TE, $3,500 \mathrm{~ms} / 63 \mathrm{~ms}$; section thickness, $5 \mathrm{~mm}$; FOV, $180 \mathrm{~mm} \times 180 \mathrm{~mm} \times 89 \mathrm{~mm}$; b values, 0 and $1,000 \mathrm{~s} / \mathrm{mm}^{2} ;$ and scan time, $30 \mathrm{~s}$.

\section{Oxygen Extraction Fraction Determination}

Oxygen extraction fraction was calculated as follows:

$$
\mathrm{OEF}=(\mathrm{Ya}-\mathrm{Yv}) / \mathrm{Ya} \times 100 \%
$$

where $\mathrm{Ya}$ and $\mathrm{Yv}$ signify arterial and venous oxygenation, respectively. Ya was measured peripherally, via pulse oximeter applied to neonatal toes. Yv was measured by TRUST MRI technique, given that blood $\mathrm{T} 2$ has a calibrationable relation with oxygenation level. This sequence utilizes a spin-labeling module to isolate pure venous blood signals, thereafter applying a series of T2-preparation pulses to modulate the MRI signal, the monoexponential fitting of which yields blood T2 (Figure 1). A T2-Yv calibration curve served to convert venous T2 to blood oxygenation, using clinically determined hematocrit values of newborns (Liu et al., 2016). Imaging slices selected for TRUST MRI were based on existing procedures (Liu et al., 2014; Qi et al., 2018), acquired parallel to intercommissural lines at a $10-\mathrm{mm}$ distance from sinus confluence [postmenstrual age (PMA) $\geq 36$ weeks] or directly through sinus confluence (PMA < 36 weeks). Other settings were as follows: labeling

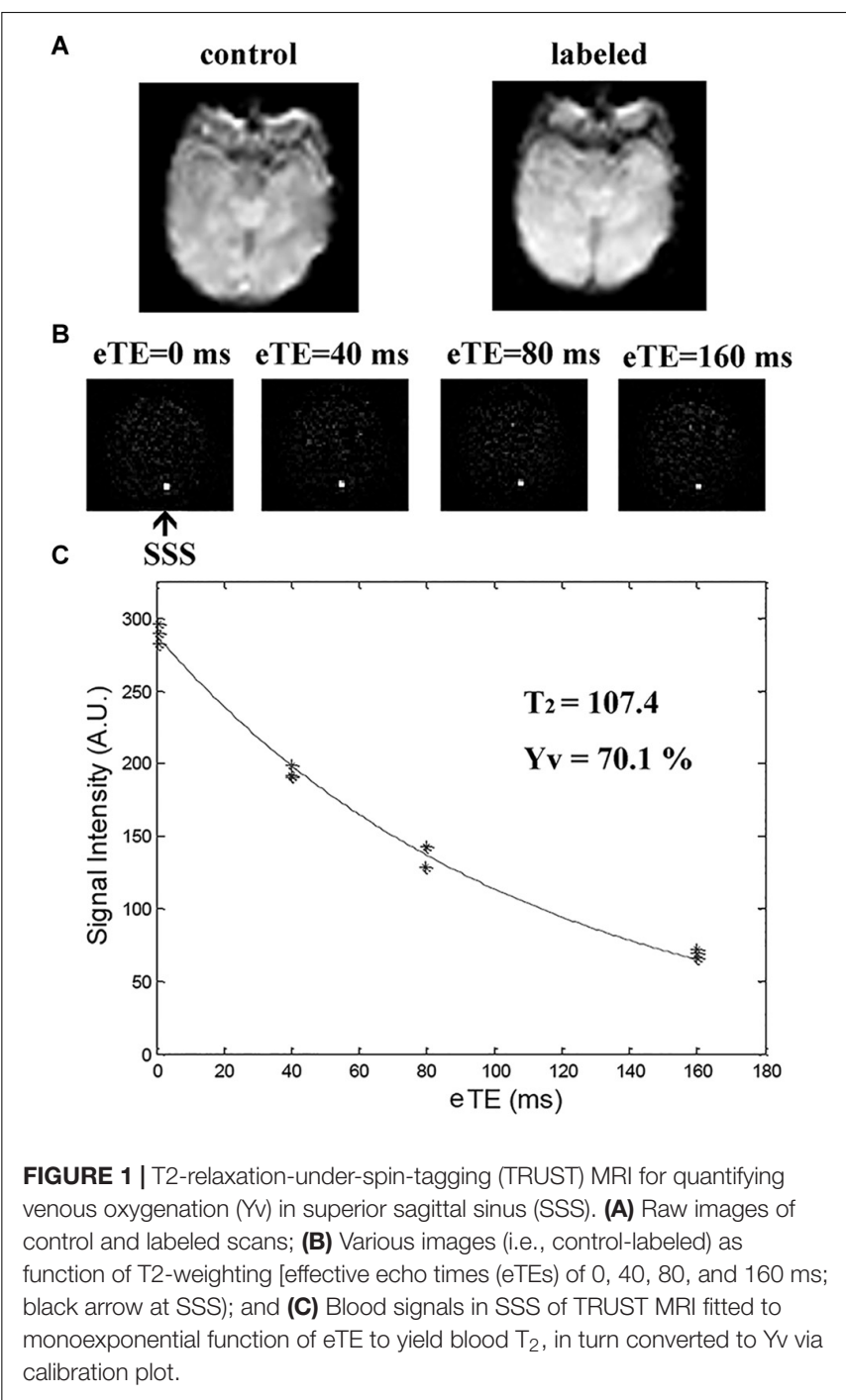

slab thickness, $80 \mathrm{~mm}$; effective TEs (eTEs), four $(0,40,80$, and $160 \mathrm{~ms}$ ); TR, $3000 \mathrm{~ms}$; inversion time (TI), $1022 \mathrm{~ms}$; FOV, 
$160 \mathrm{~mm} \times 160 \mathrm{~mm} \times 5 \mathrm{~mm}$; matrix size, $64 \times 61$; SENSE factor, 3 ; voxel size, $2.5 \mathrm{~mm} \times 2.5 \mathrm{~mm} \times 5 \mathrm{~mm}$; $\mathrm{mCPMG}, 10 \mathrm{~ms}$; eTE executions, three pairs; and total scan time, $72 \mathrm{~s}$. Processing of TRUST MRI data adhered to a previously established format (Liu et al., 2014; Qi et al., 2018; Shetty et al., 2019). Global Yv values and Ya values together provided OEF estimates.

\section{Cerebral Blood Flow Determination}

For measuring CBF, PC MRI employed bipolar gradients to encode flow velocities of blood supplying major feeding arteries of the brain, specifically left and right internal carotid arteries (LICA and RICA) and left and right vertebral arteries (LVA and RVA), allowing quantitation of total blood flow to the brain. Flow values were then normalized to brain volume, expressing $\mathrm{CBF}$ in units of $\mathrm{mL} / 100 \mathrm{~g} / \mathrm{min}$. Time-of-flight MR angiograms (TOF-MRAs) were first performed to allow visualization of above-referenced feeding arteries. Imaging slabs were positioned at center of epistropheus, with $60-\mathrm{mm}$ saturation slabs placed above to suppress venous signals. Settings of TOF MRA were as follows: TR/TE, $20 \mathrm{~ms} / 3.45 \mathrm{~ms}$; flip angle, $18^{\circ}$; FOV, $90 \mathrm{~mm} \times 90 \mathrm{~mm} \times 20 \mathrm{~mm}$; voxel size, $0.8 \mathrm{~mm} \times 0.8 \mathrm{~mm} \times 2 \mathrm{~mm}$; and scan duration, $23.7 \mathrm{~s}$.

Based on MRA images, four PC MRI scans were performed by orienting imaging slices perpendicular to and centered on respective target arteries, as previously described (Liu et al., 2014; Qi et al., 2018). Scans of LICA and RICA took place at level of foramen magnum, whereas the LVA and RVA imaging slices were placed immediately below epistropheus, away from pivot points (Figure 2) and at the following settings: slices, single; voxel size, $0.5 \mathrm{~mm} \times 0.5 \mathrm{~mm} \times 3 \mathrm{~mm}$ FOV, $180 \mathrm{~mm} \times 180 \mathrm{~mm} \times 3 \mathrm{~mm}$; maximum velocity encoding, $20 \mathrm{~cm} / \mathrm{s}$ (non-gated); and averages, 2. Total scan duration for four arteries was $1.5 \mathrm{~min}$.

Processing of PC MRI data again followed existing procedures (Liu et al., 2014; Shetty et al., 2019). Manual delineations of LICA, RICA, LVA, and RVA were achievable on magnitude images of respective PC scans, gauging levels of vascular flux by applying

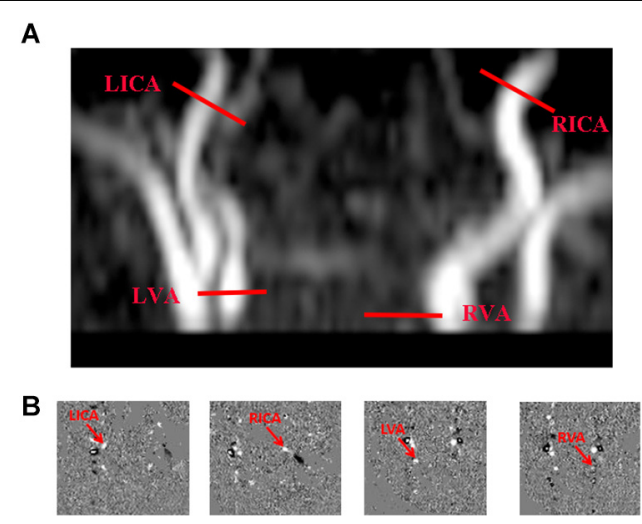

FIGURE 2 | Cerebral blood flow determination via phase-contrast (PC) MRI. (A) Slice positions overlaid on angiogram image (each red bar indicating imaging slice of one PC MRI scan), performing four PC MRI scans in each subject to assess internal carotid arteries (left, LICA; right, RICA) and vertebral arteries (left, LVA; right, RVA), respectively; and (B) Corresponding PC MRI images (delayed).
ROI masks to velocity maps (Figure 2). The sum of fluxes in all vessels ultimately yielded whole-brain blood flow $(\mathrm{mL} / \mathrm{min})$. To convert this value to $\mathrm{CBF}$, we determined brain volume through manual tracing of T2WI views, based on presumptive parenchymal density of $1.06 \mathrm{~g} / \mathrm{mL}$ (Liu et al., 2016). CBF was then calculated as total flux divided by brain weight, expressed in $\mathrm{mL} / 100 \mathrm{~g} / \mathrm{min}$.

\section{$\mathrm{CMRO}_{2}$ Calculation}

Once OEF and CBF were determined, $\mathrm{CMRO}_{2}$ was calculated according to Fick's principle (Herscovitch et al., 1985; Burgess et al., 2018):

$$
\mathrm{CMRO}_{2}=\mathrm{CBF} \times \mathrm{OEF} \times \mathrm{Ya} \times \mathrm{Ca},
$$

where $\mathrm{Ca}$ is the oxygen-carrying capacity of blood, presumptively $897 \mu \mathrm{mol} \mathrm{O}_{2} / 100 \mathrm{~mL}$ at a hematocrit of $44 \%$ (Liu et al., 2013), and $\mathrm{CMRO}_{2}$ is expressed as $\mu \mathrm{mol} \mathrm{O} / 2100 \mathrm{~g} / \mathrm{min}$. Neonatal Ca values were subject-specific, based on individual hematocrit levels.

\section{Statistical Analysis}

Linear regression analysis was undertaken to examine reliance of physiologic parameters (dependent variables) on scan age, sex, and diagnostic group (independent variables). In regression analyses, paired groups were encoded as follows: LBW-VLBW (0) vs term (1) neonates; LBW-VLBW-a (1) vs LBW-VLBWn (0) subsets; LBW-VLBW-a neonates (1) vs term controls (0); and LBW-VLBW-n neonates (0) vs term controls (1). LBWVLBW newborns underwent MRI scans once their vital signs had stabilized, and ventilators were no longer required (3 weeks old on average). Term infants had good vital signs and were amenable to scanning at any time (1 week old on average). There were distinct chronologic differences in scan ages of these pairings. Due to remarkable disparities (Table 1), it was necessary to correct birth weight, $\mathrm{CMRO}_{2}, \mathrm{CBF}, \mathrm{OEF}$, and brain volume determinations of LBW-VLBW and term neonates for scan age and sex prior to comparisons. For instance, corrected OEF was calculated as follows:

$$
\text { Corrected OEF }=\mathrm{OEF}-\mathrm{b}_{1} \times(\text { age }-\overline{\mathrm{age}})-\mathrm{b}_{2} \times(\operatorname{sex}-\overline{\operatorname{sex}})
$$

where coefficients $b_{1}$ and $b_{2}$ were based on results of an age- and sex-adjusted regression model similarly reported (Peng et al., 2014). Corrected birth weights, other physiologic parameters, and brain volumes of LBW-VLBW and term neonates were compared using independent-samples $t$-test, separately comparing LBW-VLBW $(n=41)$ and term neonates $(n=9)$, LBW-VLBW-a $(n=24)$ and LBW-VLBW-n $(n=17)$ subsets, LBW-VLBW-a neonates $(n=24)$ and term controls ( $n=24)$, and LBW-VLBW-n neonates $(n=17)$ and term controls $(n=24)$. We also analyzed birth weight, brain volume, and cerebral physiologic parameters independently, generating receiver operating characteristic (ROC) curves to distinguish the LBW-VLBW-a subset from all other neonates and from the LBW-VLBW group overall. Interrater variations in MRI scores determined by YQ and XYS were assessed via intraclass correlation coefficient (ICC), rated 
TABLE 2 | Clinical characteristics and diagnostic outcomes of LBW-VLBW-a and LBW-VLBW-n neonatal subsets.

\begin{tabular}{|c|c|c|c|c|c|}
\hline & $(n=24)$ & $\begin{array}{l}\text { LBW-VLBW-a } \\
\qquad(n=17)\end{array}$ & LBW-VLBW-n & $\mathrm{z} / \chi^{2}$ & $p$-Value \\
\hline \multirow[t]{12}{*}{ Clinical characteristics } & Males & $13(54.2)$ & $14(82.4)$ & -4.1 & $0.04^{*}$ \\
\hline & VLBW & $16(66.7)$ & $6(35.3)$ & 0.2 & 0.64 \\
\hline & Birth weight, g & $1788.2 \pm 437.9$ & $1597.8 \pm 332.9$ & 1.6 & 0.12 \\
\hline & Birth age, weeks & $32.4 \pm 2.4$ & $31.8 \pm 2.5$ & 0.7 & 0.49 \\
\hline & Scan age, weeks & $35.6 \pm 2.3$ & $35.0 \pm 2.4$ & 0.8 & 0.42 \\
\hline & Premature rupture of membranes & $6(25.0)$ & $3(17.6)$ & & \\
\hline & Twins & $2(8.3)$ & $1(5.9)$ & & \\
\hline & Umbilical cord around neck & $1(4.2)$ & $1(5.9)$ & & \\
\hline & Placenta previa & $1(4.2)$ & 0 & & \\
\hline & Fetal growth restriction & 0 & $1(5.9)$ & & \\
\hline & Disappearance of umbilical blood flow & 0 & $1(5.9)$ & & \\
\hline & Reverse umbilical blood flow & 0 & $1(5.9)$ & & \\
\hline \multirow[t]{4}{*}{ MRI findings } & White matter damage & $20(83.3)$ & 0 & & \\
\hline & Subarachnoid hemorrhage & $2(8.3)$ & 0 & & \\
\hline & Intraventricular hemorrhage (IVH) & $1(4.2)$ & 0 & & \\
\hline & Cerebral infarction & $1(4.2)$ & 0 & & \\
\hline \multirow[t]{6}{*}{ Blood gas analysis } & Total tested & $21(87.5)$ & $15(88.2)$ & & \\
\hline & $\mathrm{pH}$ & $7.4 \pm 0.06$ & $7.4 \pm 0.06$ & 0.4 & 0.67 \\
\hline & $\mathrm{PCO}_{2}, \mathrm{mmHg}$ & $41.9 \pm 7.3$ & $45.0 \pm 7.2$ & -1.2 & 0.22 \\
\hline & $\mathrm{PaO}_{2}, \mathrm{mmHg}$ & $87.9 \pm 7.0$ & $86.0 \pm 6.6$ & 0.8 & 0.42 \\
\hline & $\mathrm{SaO}_{2}, \%$ & $95.0 \pm 7.4$ & $94.6 \pm 4.7$ & 1.0 & 0.92 \\
\hline & Glucose, mmol/L & $4.5 \pm 1.3$ & $4.6 \pm 1.1$ & -1.0 & 0.30 \\
\hline \multirow[t]{4}{*}{ Physiologic Parameters } & OEF, \% & $29.3 \pm 11.9$ & $34.2 \pm 7.4$ & -1.5 & 0.14 \\
\hline & $\mathrm{CMRO}_{2}, \mu \mathrm{mol} / 100 \mathrm{~g} / \mathrm{min}$ & $28.2 \pm 12.8$ & $32.2 \pm 9.1$ & -1.1 & 0.28 \\
\hline & $\mathrm{CBF}, \mathrm{mL} / 100 \mathrm{~g} / \mathrm{min}$ & $13.1 \pm 5.8$ & $14.4 \pm 3.5$ & -0.8 & 0.41 \\
\hline & Brain volume, $\mathrm{mL}$ & $273.8 \pm 86.1$ & $252.9 \pm 54.4$ & 0.9 & 0.38 \\
\hline
\end{tabular}

Data expressed as $n$ (\% total) or mean \pm standard deviation.

${ }^{*} P<0.05$.

$\mathrm{OEF}$, oxygen extraction fraction; $\mathrm{CMRO}_{2}$, cerebral metabolic rate of oxygen; CBF, cerebral blood flow; $L B W$-VLBW, low birth-weight/very low birth-weight; $L B W$-VLBW-a, LBW-VLBW newborns with abnormal structural MRIs; LBW-VLBW-n, LBW-VLBW newborns with normal structural $M R I s ; P C \mathrm{O}_{2}$, partial pressure of carbon dioxide; PaO 2 , partial pressure of oxygen; $\mathrm{SaO}_{2}$, oxygen saturation.

as follows: $1.0-0.81$, excellent; $0.80-0.61$, very good; $0.60-$ 0.41 , good; $0.40-0.21$, reasonable; and $0.20-0.00$, poor. All computations were driven by standard software (SPSS v21; IBM Corp, Armonk, NY, United States), setting significance at $p<0.05$.

\section{RESULTS}

\section{Characteristics of Study Population}

In LBW-VLBW and term neonates, measured parameters were as follows: OEF, $31.3 \pm 10.5 \%$ vs $30.8 \pm 6.2 \%$ $(p=0.89) ; \quad \mathrm{CMRO}_{2}, \quad 29.9 \pm 11.4 \mu \mathrm{mol} / 100 \mathrm{~g} / \mathrm{min}$ vs $48.9 \pm 12.4 \mu \mathrm{mol} / 100 \mathrm{~g} / \mathrm{min}(p<0.001) ; \mathrm{CBF}$, $13.6 \pm 5.0 \mathrm{~mL} / 100 \mathrm{~g} / \mathrm{min}$ vs $19.5 \pm 3.8 \mathrm{~mL} / 100 \mathrm{~g} / \mathrm{min}(p=0.002)$; and brain volume, $265.2 \pm 74.5 \mathrm{~mL}$ vs $354.1 \pm 52.0 \mathrm{~mL}$ $(p=0.001)$. Only OEF proved similar, the other parameters differing significantly by group.

Population characteristics and diagnostic outcomes (i.e., MRI findings, blood gas results, and physiologic parameters) of the LBW-VLBW group $(n=41)$, including both LBW-VLBWa and LBW-VLBW-n subsets, are detailed in Table 2 and
Figures 3A-I. Term controls included nine neonates, each undergoing clinically indicated MRI based on certain clinical signs/symptoms, umbilical cord blood gas analysis, or other routine blood testing at birth. However, no MRI abnormalities were observed, ostensibly excluding any nervous system diseases (Figures 3J-L). The inter-rater ICC value of MRI scoring was 0.9 , indicating excellent reliability. There were six infants lacking blood gas analysis within $24 \mathrm{~h}$ after MRI scans. All values were similar for the LBW-VLBW and term groups and both LBW-VLBW subsets (LBW-VLBW-a and LBW-VLBWn) $(p>0.05)$. Fifteen LBW-VLBW newborns had required mechanical ventilation.

\section{Cerebral Metabolism and Hemodynamics According to Group}

We first compared physiologic measures of LBW-VLBW and term neonates (Table 3). Although $\mathrm{CMRO}_{2}$ was significantly lower $(p=0.01)$ in LBW-VLBW (vs term) newborns, CBF $(p=0.06)$ and OEF $(p=0.67)$ did not differ significantly. Furthermore, $\mathrm{CMRO}_{2}(p=0.48)$ and $\mathrm{CBF}(p=0.63)$ failed to show scan age-related increases during this period of early development; and despite significant differences in birth weight, 


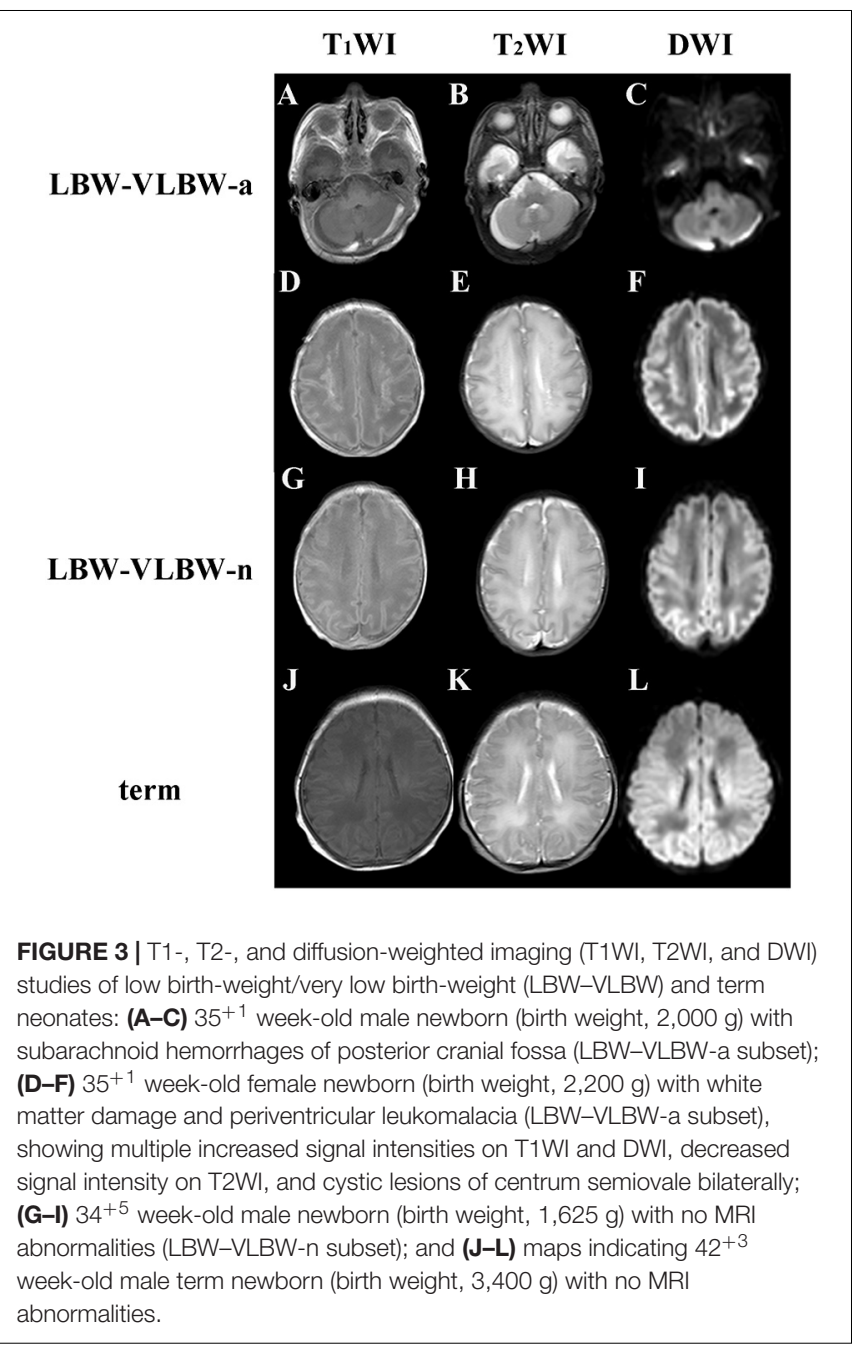

LBW-VLBW and term neonates did not differ significantly in brain volume.

Next, we compared the two subsets of LBW-VLBW neonates (LBW-VLBW-a and LBW-VLBW-n) with term newborns, both displaying lower $\mathrm{CMRO}_{2}$ rates relative to controls $(p=0.03$ and $p=0.04$, respectively). Contrary to expectations, no significant differences in $\mathrm{CMRO}_{2}(p=0.30)$, CBF $(p=0.50)$, or OEF ( $p=0.15)$ recordings were evident across subsets upon linear regression analysis. Relative to term neonates, OEF was significantly lower $(p=0.02)$ in the LBW-VLBW-n subset.

Table 3 lists results of coefficients $\left(b_{1}\right.$, scan age; $b_{2}$, sex), with $95 \%$ confidence interval (CI) of coefficients and respective $p$-values. Once corrected for scan age and sex, group comparisons of birth weight, $\mathrm{CMRO}_{2}, \mathrm{CBF}, \mathrm{OEF}$ and brain volume produced similar results (Table 4 and Figure 4). Corrected $\mathrm{CMRO}_{2}$ and CBF differed significantly in LBW-VLBW vs term neonates ( $p<0.001$ and $p=0.007$, respectively), the LBW-VLBW-a subset vs term controls ( $p=0.001$ and $p=0.011$, respectively), and the LBW-VLBW-n subset vs term controls $(p<0.001$ and $p=0.021$, respectively). This suggests that observed differences in physiologic parameters $\left(\mathrm{CMRO}_{2}\right.$ and $\left.\mathrm{CBF}\right)$ of the LBW-VLBW-a subset and term controls stemmed from brain injuries and did not reflect scan age or sex. Corrected OEF values in the LBW-VLBW-n subset did differ significantly $(p<0.001)$ from those of term controls. There were no significant differences in corrected values of LBW-VLBW-a and LBW-VLBW-n subsets $(p>0.05)$.

\section{ROC Analysis for Distinguishing LBW-VLBW Neonates With Structural MRI Abnormalities}

Receiver operating characteristic curves for birth weight [area under the curve $(\mathrm{AUC})=0.6,95 \%$ confidence interval $(\mathrm{CI}): 0.4-$ $0.8 ; p=0.25]$, OEF (AUC $=0.7,95 \% \mathrm{CI}: 0.5-0.8 ; p=0.04$ ), $\mathrm{CMRO}_{2}(\mathrm{AUC}=0.7,95 \%$ CI: 0.6-0.9; $p=0.007), \mathrm{CBF}$ (AUC $=0.7,95 \% \mathrm{CI}: 0.5-0.8 ; p=0.02)$, and brain volume $(\mathrm{AUC}=0.5,95 \% \mathrm{CI}: 0.5-0.7 ; p=0.53)$ in distinguishing the LBW-VLBW-a subset from term and LBW-VLBW neonates are shown in Figure 5A. OEF, $\mathrm{CBF}$ and $\mathrm{CMRO}_{2}$ demonstrated fair diagnostic performance in this regard.

Receiver operating characteristic curves for birth weight $(\mathrm{AUC}=0.6,95 \% \mathrm{CI}: 0.5-0.6 ; p=0.19), \mathrm{OEF}(\mathrm{AUC}=0.7$, 95\% CI: $0.5-0.9 ; p=0.03), \mathrm{CMRO}_{2}(\mathrm{AUC}=0.6,95 \% \mathrm{CI}: 0.5-$ $0.8 ; p=0.17), \mathrm{CBF}(\mathrm{AUC}=0.6,95 \% \mathrm{CI}: 0.5-0.8 ; p=0.20)$, and brain volume $(\mathrm{AUC}=0.6,95 \% \mathrm{CI}: 0.5-0.6 ; p=0.22)$ in distinguishing LBW-VLBW-a neonates from LBW-VLBW neonates are shown in Figure 5B. Interesting, only OEF displayed fair diagnostic performance. MRI physiologic parameters also appeared to outperform brain volume or body weight.

\section{DISCUSSION}

To our knowledge, the present study is the first to evaluate oxygen consumption and CBF in LBW and VLBW preterm neonates using TRUST and PC MRI. Our data suggest that even in the absence of structural abnormalities, LBW and VLBW preterm newborns generally have lower metabolism and CBF, showing pronounced deficits in these physiologic parameters. Compared with conventional measures (i.e., birth weight or brain volume), OEF provided greater power to distinguish LBW-VLBW preterm neonates with structural MRI abnormalities.

\section{Physiologic and Clinical Considerations}

A major finding of this study was that LBW-VLBW newborns with normal or abnormal structural MRI have similar rates of oxygen consumption and $\mathrm{CBF}$. After correcting for scan age, their $\mathrm{CMRO}_{2}$ and $\mathrm{CBF}$ rates were still lower than those of healthy term neonates. In reviewing our LBW-VLBW infants overall (regardless of MRI status), we found that most had experienced dyspnea or hypoxemia. Given the abundance of mitochondria in cerebral capillaries, there was likely hypoxic damage to capillary walls, affecting autoregulation of CBF. The passive expansion of vascular channels that results and alters cerebral hemodynamics (Odell et al., 2006).

Premature and LBW newborns also have immature cerebrovascular systems. Once disruptions in oxygen supply and 
TABLE 3 | Regression analysis of LBW-VLBW (LBW-VLBW-a + LBW-VLBW-n) and term neonates.

\begin{tabular}{|c|c|c|c|c|c|c|c|c|c|c|}
\hline & & \multicolumn{3}{|c|}{$p$-Value } & \multicolumn{3}{|c|}{ Coefficients (b1,2) } & \multicolumn{3}{|c|}{$95 \% \mathrm{Cl}$ of Coefficients } \\
\hline & & Scan age & Sex & Group & Scan age & Sex & Group & Scan age & Sex & Group \\
\hline \multirow[t]{5}{*}{ LBW-VLBW and term neonates } & Birth weight & 0.93 & 0.31 & $<0.001^{*}$ & 2.8 & 159.0 & -1755.6 & -61.4 to 67.0 & -150.8 to 468.8 & -2265.8 to 1245.4 \\
\hline & OEF & 0.67 & 0.59 & 0.67 & 0.3 & -1.7 & 2.3 & -1.1 to 1.6 & -8.2 to 4.7 & -8.3 to 12.8 \\
\hline & $\mathrm{CMRO}_{2}$ & 0.48 & 0.54 & $0.01^{*}$ & 0.6 & -2.3 & -15.7 & -1.0 to 2.1 & -9.8 to 5.2 & -28.1 to 3.4 \\
\hline & $\mathrm{CBF}$ & 0.63 & 0.46 & 0.06 & 0.2 & -1.2 & -4.9 & -0.5 to 0.8 & -4.3 to 2.0 & -10.0 to 0.2 \\
\hline & Brain volume & $<0.001^{\star}$ & 0.10 & 0.65 & 18.3 & -31.7 & 14.4 & 10.3 to 26.2 & -70.0 to 6.7 & -48.8 to 77.6 \\
\hline \multirow[t]{5}{*}{ LBW-VLBW-a and LBW-VLBW-n subsets } & Birth weight & 0.47 & 0.63 & 0.25 & 21.5 & 71.4 & 157.2 & -37.6 to 80.7 & -225.1 to 368.0 & -113.5 to 427.9 \\
\hline & OEF & 0.76 & 0.99 & 0.15 & 0.2 & 0.1 & -5.1 & -1.3 to 1.8 & -7.7 to 7.8 & -12.2 to 2.0 \\
\hline & $\mathrm{CMRO}_{2}$ & 0.37 & 0.74 & 0.30 & 0.8 & -1.4 & -4.0 & -0.9 to 2.5 & -9.9 to 7.1 & -11.8 to 3.8 \\
\hline & CBF & 0.75 & 0.66 & 0.50 & 0.1 & -0.8 & -1.2 & 0.6 to 0.9 & -4.6 to 2.9 & -4.6 to 2.3 \\
\hline & Brain volume & $<0.001^{\star}$ & 0.03 & 0.30 & 22.6 & -45.4 & 20.0 & 14.3 to 31.0 & -87.3 to 3.6 & -18.2 to 58.2 \\
\hline \multirow[t]{5}{*}{ LBW-VLBW-a subset and term neonates } & Birth weight & 0.74 & 0.73 & $<0.001^{*}$ & 15.1 & 73.9 & -806.0 & -78.4 to 108.7 & -352.1 to 499.9 & -1147.4 to 464.5 \\
\hline & OEF & 0.64 & 0.77 & 0.55 & -4.3 & 1.2 & -2.0 & -2.3 to 1.4 & -7.3 to 9.7 & -8.8 to 4.8 \\
\hline & $\mathrm{CMRO}_{2}$ & 0.60 & 0.99 & $0.03^{*}$ & 0.6 & -0.09 & -8.8 & -1.6 to 2.8 & -10.1 to 10 & -16.9 to 0.8 \\
\hline & $\mathrm{CBF}$ & 0.77 & 0.84 & 0.10 & 0.1 & -0.4 & -2.8 & -0.8 to 1.1 & -4.7 to 3.8 & -6.2 to 0.6 \\
\hline & Brain volume & $0.004^{*}$ & 0.21 & 0.62 & 18.0 & -34.2 & 10.7 & 6.1 to 29.9 & -88.2 to 19.9 & -32.6 to 54.0 \\
\hline \multirow[t]{5}{*}{ LBW-VLBW-n subset and term neonates } & Birth weight & 0.34 & 0.34 & $<0.001^{*}$ & -45.4 & 257.2 & -2115.3 & -142.4 to 51.5 & -285.6 to 800.1 & -2828.4 to 1402.3 \\
\hline & OEF & $0.03^{*}$ & 0.23 & $0.02^{*}$ & 1.4 & -4.0 & 11.1 & 0.2 to 2.6 & -10.8 to 2.8 & 2.2 to 20.0 \\
\hline & $\mathrm{CMRO}_{2}$ & 0.74 & 0.47 & $0.04^{*}$ & 0.3 & -4.0 & -15.1 & -1.7 to 2.3 & -15.1 to 7.2 & -29.7 to 0.4 \\
\hline & $\mathrm{CBF}$ & 0.41 & 0.39 & 0.16 & 0.3 & -1.6 & -3.6 & -0.4 to 1.0 & -5.5 to 2.2 & -8.7 to 1.5 \\
\hline & Brain volume & $0.02^{*}$ & 0.21 & 0.25 & 11.1 & -31.8 & -38.1 & 2.0 to 20.2 & -82.7 to 19.2 & -105.0 to 28.8 \\
\hline
\end{tabular}

${ }^{*} p<0.05$

$\mathrm{Cl}$, confidence interval; OEF, oxygen extraction fraction; $\mathrm{CMRO}_{2}$, cerebral metabolic rate of oxygen; CBF, cerebral blood flow; $L B W$-VLBW, low birth-weight/very low birth-weight; $L B W$-VLBW-a, $L B W$-VLBW newborns with abnormal structural MRIs; LBW-VLBW-n, LBW-VLBW newborns with normal structural MRIs. 
TABLE 4 | Corrected parameters for LBW-VLBW neonates/subsets and term controls.

\begin{tabular}{|c|c|c|c|c|c|c|}
\hline Comparators & & Birth weight, g & OEF, \% & $\mathrm{CMRO}_{2}, \mu \mathrm{mol} / 100 \mathrm{~g} / \mathrm{min}$ & $\mathrm{CBF}, \mathrm{mL} / 100 \mathrm{~g} / \mathrm{min}$ & Brain volume, $\mathrm{mL}$ \\
\hline LBW-VLBW & & $1708.6 \pm 396.9$ & $31.6 \pm 10.4$ & $30.5 \pm 11.3$ & $13.8 \pm 5.0$ & $283.8 \pm 56.3$ \\
\hline \multirow[t]{3}{*}{ Term } & & $3464.2 \pm 751.9$ & $29.3 \pm 6.0$ & $46.2 \pm 12.5$ & $18.7 \pm 3.7$ & $269.4 \pm 69.9$ \\
\hline & $\mathbf{t}$ & 10.0 & -0.6 & 3.7 & 2.8 & -0.7 \\
\hline & $p$ & $<0.001^{\star}$ & 0.53 & $<0.001^{*}$ & $0.007^{\star}$ & 0.51 \\
\hline LBW-VLBW-a & & $1774.4 \pm 426.7$ & $29.2 \pm 12.0$ & $28.2 \pm 12.7$ & $13.2 \pm 5.8$ & $273.5 \pm 65.5$ \\
\hline \multirow[t]{3}{*}{ LBW-VLBW-n } & & $1616.7 \pm 337.3$ & $34.3 \pm 7.1$ & $32.2 \pm 8.9$ & $14.3 \pm 3.5$ & $253.5 \pm 35.9$ \\
\hline & $\mathbf{t}$ & 1.3 & -1.6 & -1.1 & -0.7 & 1.1 \\
\hline & $p$ & 0.21 & 0.13 & 0.27 & 0.47 & 0.26 \\
\hline LBW-VLBW-a & & $1804.8 \pm 429.2$ & $28.6 \pm 11.8$ & $29.1 \pm 12.7$ & $13.3 \pm 5.8$ & $301.6 \pm 67.4$ \\
\hline \multirow[t]{3}{*}{ Term } & & $3416.7 \pm 762.0$ & $32.6 \pm 6.6$ & $46.7 \pm 12.5$ & $19.0 \pm 3.7$ & $280.2 \pm 69.5$ \\
\hline & $\mathbf{t}$ & -7.7 & -1.0 & -3.6 & -2.7 & 0.8 \\
\hline & $p$ & $<0.001^{*}$ & 0.34 & $0.001^{\star}$ & $0.011^{*}$ & 0.43 \\
\hline LBW-VLBW-n & & $1510.4 \pm 320.5$ & $36.9 \pm 6.2$ & $32.8 \pm 8.8$ & $15.0 \pm 3.4$ & $274.8 \pm 38.2$ \\
\hline \multirow[t]{3}{*}{ Term } & & $3625.9 \pm 729.6$ & $25.7 \pm 6.1$ & $47.8 \pm 12.4$ & $18.5 \pm 3.7$ & $312.9 \pm 59.8$ \\
\hline & $\mathbf{t}$ & -10.3 & 4.4 & -3.6 & -2.5 & -2.0 \\
\hline & $p$ & $<0.001^{\star}$ & $<0.001^{\star}$ & $<0.001^{\star}$ & $0.021^{\star}$ & 0.06 \\
\hline
\end{tabular}

Data expressed as mean \pm standard deviation.

${ }^{*} p<0.05$.

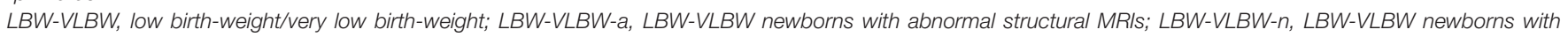
normal structural MRIs.

metabolism occur, $\mathrm{CMRO}_{2}$ may decline accordingly, increasing the prospect of brain injuries due to poor cerebrovascular function. This perhaps explains the comparatively low $\mathrm{CMRO}_{2}$ and CBF rates in both LBW-VLBW-a and LBW-VLBW-n subsets. However, the significantly higher OEF of the LBWVLBW-n subset (vs term control) is worthy of attention. It may be that once cerebral autoregulation is exhausted by hypoxia, CBF peaks and will change only marginally in response to increased oxygen demand. OEF then progressively increases to maintain constant $\mathrm{CMRO}_{2}$ levels. Hence, OEF may be a more comprehensive indicator of tissue-level brain impairment than $\mathrm{CBF}$.

We observed a trend towards reduction of OEF in the LBWVLBW-a subset, which was not consistent with previous clinical observations. Relative to controls (ductus arteriosus without cerebral pathology: OEF, $25 \pm 2 \%$ ), VLBW preterm neonates with post-hemorrhagic ventricular dilatation (PHVD) have shown significant OEF elevation (36 \pm 3\%) (McLachlan et al., 2017). Differences in scan age and patient sampling may account for this disparity.

In light of our findings, it seems that normal morphology on brain MRI does not ensure normal metabolic and hemodynamic cerebral physiology in LBW-VLBW preterm newborns. Our data offer support for Laptook's discovery that nearly $30 \%$ of extremely LBW infants with normal head ultrasound studies experienced adverse neurodevelopmental outcomes, including cerebral palsy (Laptook et al., 2005). Furthermore, there are other physiologic variables, namely blood gas analytes $\left(\mathrm{pH}, \mathrm{PCO}_{2}, \mathrm{PaO}_{2}\right)$, glucose concentration, required pressers, or mechanical ventilation, that may impact cerebrovascular hemodynamics at time of MRI. We limited scanning of neonates to those no longer requiring ventilation, whose vital signs were stable. Thus, our blood gas data were similar across groups. Overall, this endeavor was preliminary in nature, forming a basis for continued research on this complex issue.

\section{Technical Considerations}

Phase-contrast MRI and oxygenation MRI have been previously applied to study $\mathrm{OEF}, \mathrm{CMRO}_{2}$, and $\mathrm{CBF}$ in healthy neonates and those with HIE (Liu et al., 2014; Shetty et al., 2019), as summarized in Table 5. The physiologic parameters we measured in term newborns with no structural MRI defects were generally aligned with those reported in healthy infants by others (Liu et al., 2014), although our $\mathrm{CMRO}_{2}$ and $\mathrm{CBF}$ appeared slightly higher $(48.9 \pm 12.4 \mathrm{~mL} / 100 \mathrm{~g} / \mathrm{min}$ vs $38.3 \pm 17.7 \mathrm{~mL} / 100 \mathrm{~g} / \mathrm{min}$; $19.5 \pm 3.8 \mathrm{~mL} / 100 \mathrm{~g} / \mathrm{min}$ vs $13.4 \pm 4.2 \mathrm{~mL} / 100 \mathrm{~g} / \mathrm{min})$. Differences in scan age and birth weight may have skewed the results to some extent. Compared with our term controls, the LBW-VLBW-a subset displayed lower OEF, $\mathrm{CMRO}_{2}$, and CBF determinations, comparable to results reported by Shetty in neonates with HIE (Shetty et al., 2019). The similar OEF, $\mathrm{CMRO}_{2}$, and $\mathrm{CBF}$ outcomes reached in our LBW-VLBW-n subset with normal structural MRIs were also in agreement with values achieved through previous NIRS, ASL, and TRUST studies focused on newborns with hypotensive, PHVD, or HIE conditions (Table 4; Munro et al., 2004; De Vis et al., 2014; McLachlan et al., 2017). Consequently, the accuracy and reliability of TRUST and PC MRI in neonatal assessments of this sort is validated.

\section{Relations Between Physiologic Parameters and Scan Age}

Unlike previous reports (Liu et al., 2014; Qi et al., 2018), we found that $\mathrm{CMRO}_{2}$ and $\mathrm{CBF}$ did not increase with scan age. Past investigations may have involved large differences in scan age, 


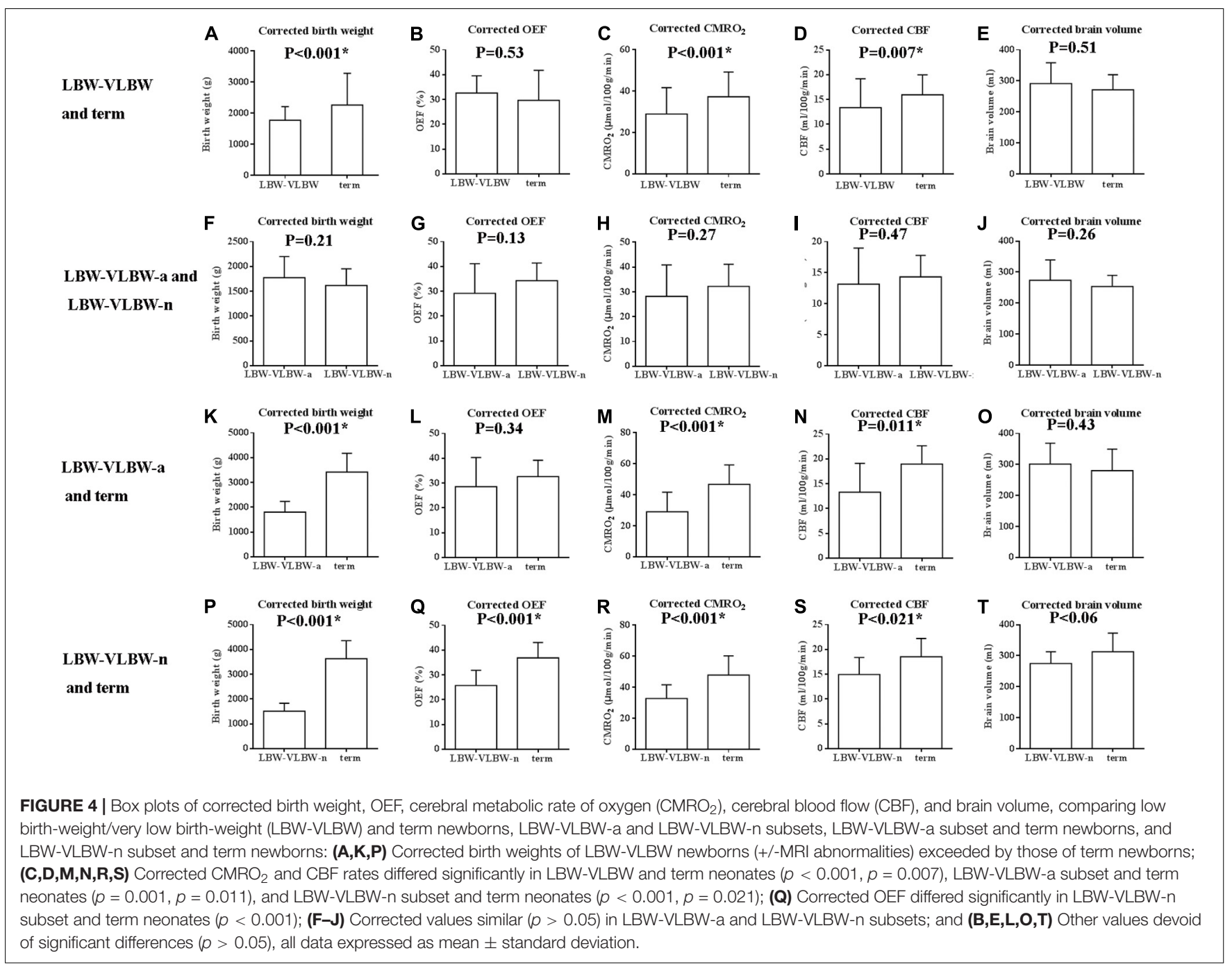

birth weight, and cerebral autoregulatory capacities of preterm LBW-VLBW and term newborns.

\section{AUC Values of Physiologic Parameters in LBW-VLBW Newborns With Structural MRI Abnormalities}

Our data indicated that physiologic parameters outperformed morphologic indices of brain volume and birth weight in distinguishing neonates of the LBW-VLBW-a subset, showing higher AUC values. Although T1- and T2-weighted scans readily exposed structural abnormalities in LBW-VLBW neonates, they offered no insights into related pathophysiologic changes and etiologies. Compared with term neonates, the reduced cerebral blood supply and oxygen metabolism observed in perinatal LBW-VLBW infants may be pathophysiologic precursors of morphologic changes, potentially linked to adverse neurodevelopmental outcomes. If OEF significantly declines after decompensation of CBF autoregulation, morphologic MRI abnormalities may then emerge. Our ROC curves confirm that $\mathrm{OEF}, \mathrm{CMRO}_{2}, \mathrm{CBF}$, and especially OEF perform fairly well in distinguishing LBW-VLBW infants with structural MRI abnormalities (Figure 5).

In summary, TRUST and PC MRI are useful methods in assessing cerebral oxygen consumption and hemodynamics in LBW-VLBW infants. LBW-VLBW neonates, with or without normal structural MRIs, still have diminished $\mathrm{CMRO}_{2}$ and $\mathrm{CBF}$, relative to healthy term neonates of corrected scan age. Abnormal sMRI studies are reflective of diminished OEF, whereas physiologic imaging may help identify LBWVLBW newborns with sMRI abnormalities and high risk of irreversible brain damage.

\section{Limitations}

It is generally acknowledged that physiologic parameters measured in localized areas of brain injury are more telling than global measurements. Thus, our global measurements may have produced false negatives in group comparisons. On the other hand, such comparisons between preterm LBW-VLBW and full-term healthy infants are apt to be more accurate if scan age is consistent. 
A

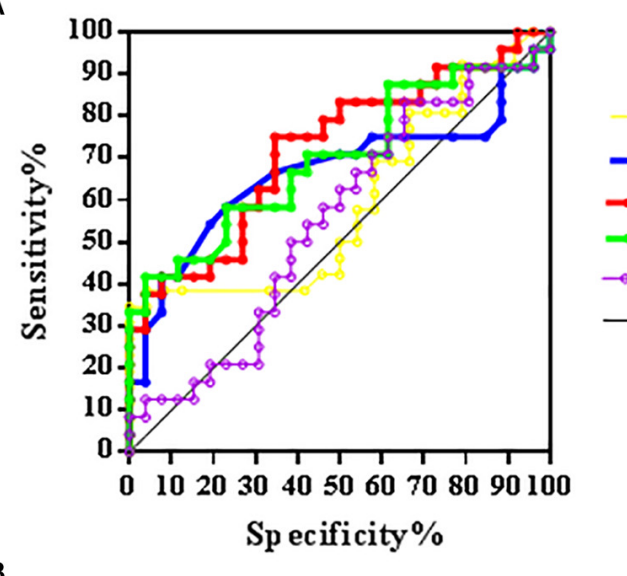

B

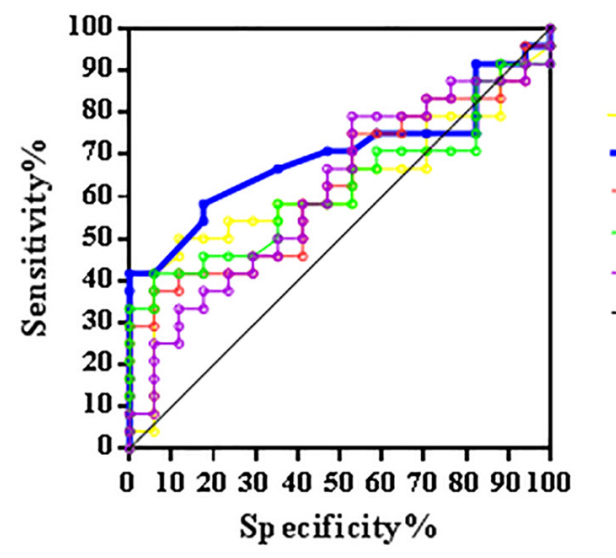

$\begin{array}{lccl} & \text { AUC } & \text { P } & 95 \% \mathrm{CI} \\ \text { Birth weight } & 0.5 & 0.25 & 0.5-0.8 \\ - \text { OEF } & 0.7 & 0.04^{\star} & 0.5-0.8 \\ -\mathrm{CMRO}_{2} & 0.7 & 0.007^{\star} & 0.6-0.9 \\ \mathrm{CBF}_{-} & 0.7 & 0.02^{\star} & 0.5-0.8 \\ \text { - Brain Volume } & 0.5 & 0.53 & 05-0.7 \\ \text { Identity } & & & \end{array}$

tity

FIGURE 5 | Receiver operating characteristic (ROC) curves for five models [birth weight, oxygen extraction fraction (OEF), cerebral metabolic rate of oxygen $\left(\mathrm{CMRO}_{2}\right)$, cerebral blood flow (CBF), and brain volume] in identifying LBW-VLBW newborns with abnormal structural MRIs (LBW-VLBW-a subset). (A) Fair utility of $\mathrm{OEF}, \mathrm{CMRO}_{2}$, and $\mathrm{CBF}$ in distinguishing members of LBW-VLBW-a subset from LBW-VLBW and term newborns and (B) Fair utility of OEF only in distinguishing members of LBW-VLBW-a subset from LBW-VLBW neonates. Higher area-under-the-curve (AUC) values for physiologic parameters, compared with morphologic indices of brain weight and volume.

Given the worldwide prevalence of LBW-VLBW neonates $(\sim 14.6 \%)$, our small population sampling seemed problematic, as did the unrestricted merging of VLBW and LBW neonates, regardless of sex. After appropriate exclusions for congenital malformations, infections, metabolic diseases, and MRI motor artifacts, we were left with only 41 qualifying newborns for the LBW-VLBW group; and the few term neonates recruited as controls required brain scans on a clinical basis [i.e., unusual symptoms/signs, prenatal history, or maternal high-risk factors (pregnancy-induced hypertension, gestational diabetes)]. Some term neonates were also discounted due to abnormal laboratory results or MRI findings. Presently, the potential for neurocognitive deficits in these infants and the relevance of $\mathrm{CMRO}_{2}$ or its threshold in relation to such deficits is unknown. $\mathrm{CMRO}_{2}$ may be a pivotal determinant of prognosis, helping to formulate reasonable therapeutic strategies.

In future research, we will likely broaden the scope of our study to include neurodevelopmental follow-up of LBWVLBW neonates, clarifying the impact of $\mathrm{CMRO}_{2}$ reductions on neurocognitive deficits. We will also bolster subject recruitment, further stratifying by birth weight (VLBW, LBW) and sex, and foster a multicenter approach to ascertain neurocognitive thresholds for reductions in $\mathrm{CMRO}_{2}$. Owing to brain immaturity, especially in VLBW infants, there is exceptional vulnerability to injuries undermining the microstructural integrity and tract connectivity of periventricular white matter (a vascular watershed territory) (Skranes et al., 2007). Knut has reported that VLBW infants exhibit smaller brain volumes and larger lateral ventricles by the age of 20 , compared with controls. Diminished gray and white matter volumes and ventricular dilatation in young adults with histories of VLBW may well signal permanent developmental handicaps after perinatal brain injury and impaired cognitive function (Bjuland et al., 2014). We must better address such lesions, adding NIRS to testing protocols for localized $\mathrm{CMRO}_{2}$ measurement, with the ultimate goal of cultivating treatment guidelines for the brain injuries that LBW-VLBW infants sustain.

It is unclear at this point whether administering an anesthetic, such as chloral hydrate, has any cerebrovascular hemodynamic ramifications. There is no direct evidence in studies of humans 


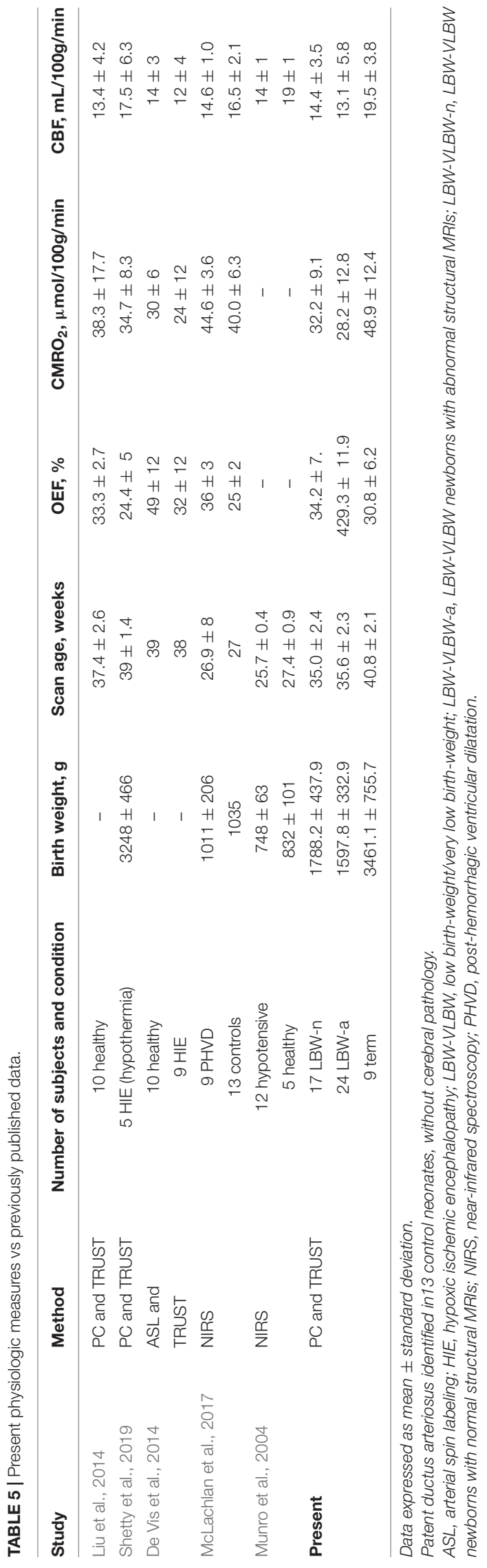

and animals that it increases CBF or lowers glucose metabolism (Grome and McCulloch, 1981; Uematsu et al., 2009). However, investigation of a non-sedated group would be worthwhile, perhaps implementing an immobilization device. Likewise, we used a pulse oximeter affixed to newborn toes in measuring Ya, as others have done (Liu et al., 2014), thus risking possible differences in pulse pressures of upper and lower limbs. The fact that we excluded newborns with congenital malformations (i.e., congenital heart disease) made this scenario less plausible. Going forward, we will use a pulse oximeter on the right hand (preductus measurement) to more accurately reflect $\mathrm{SaO}_{2}$ at brain level. Finally, the image quality in Figures 1, 2 was substandard to the rapidity of positioning and scanning. Refinement may yield more positive and interesting findings.

\section{CONCLUSION}

In the present study, we have demonstrated that structural damage in LBW-VLBW-a neonates is associated with metabolic and hemodynamic deficits of the brain. LBW-VLBW-n neonates with lower $\mathrm{CBF}$ and $\mathrm{CMRO}_{2}$, and higher OEF tended to show minimal structural abnormalities. Physiologic imaging may be a useful means of identifying those LBW-VLBW newborns at high risk of developing irreversible brain damage.

\section{DATA AVAILABILITY STATEMENT}

The raw data supporting the conclusions of this article will be made available by the authors, without undue reservation.

\section{ETHICS STATEMENT}

The study protocol had ethical approval from the Ethics Committee of Shengjing Hospital of China Medical University (IRB2015PS28K). Written informed consent from the participants' legal guardian/next of kin was not required to participate in this study in accordance with the national legislation and the institutional requirements.

\section{AUTHOR CONTRIBUTIONS}

YQ contributed study concepts and design, and providing postprocessing assistance. Both authors participated in analysis of experiment results, drafting and editing of the manuscript, and have read and approved the final manuscript for publication.

\section{FUNDING}

This study was supported by the Science and Technology Planning Project of Shenyang (No. 19-112-4-013), the Research Center for Medical Education of China Medical University (No. YDJK2020042), and the New Technology Project of Shengjing Hospital. 


\section{REFERENCES}

Barker, D. J. (2003). The developmental origins of adult disease. Eur. J. Epidemiol. 18, 733-736. doi: 10.1023/a:1025388901248

Bjuland, K. J., Rimol, L. M., Løhaugen, G. C., and Skranes, J. (2014). Brain volumes and cognitive function in very-low-birth-weight (VLBW) young adults. Eur. J. Paediatr. Neurol. 18, 578-590. doi: 10.1016/j.ejpn.2014. 04.004

Blencowe, H., Krasevec, J., de Onis, M., Black, R. E., An, X., Stevens, G. A., et al. (2019). National, regional, and worldwide estimates of low birthweight in 2015, with trends from 2000: a systematic analysis. Lancet. Global Health 7, e849-e860. doi: 10.1016/S2214-109X(18)30 565-5

Blencowe, H., Lee, A. C., Cousens, S., Bahalim, A., Narwal, R., Zhong, N., et al. (2013). Preterm birth-associated neurodevelopmental impairment estimates at regional and global levels for 2010. Pediatr. Res. 74, 17-34. doi: 10.1038/pr.2013. 204

Burgess, K. R., Lucas, S. J. E., Burgess, K. M. E., Sprecher, K. E., Donnelly, J., Basnet, A. S., et al. (2018). Increasing cerebral blood flow reduces the severity of central sleep apnea at high altitude. J. Appl. Physiol. 124, 1341-1348. doi: 10.1152/japplphysiol.00799.2017

Burns, Y. R., Danks, M., O'Callaghan, M. J., Gray, P. H., Cooper, D., Poulsen, L., et al. (2009). Motor coordination difficulties and physical fitness of extremelylow-birthweight children. Developmental Med. Child Neurol. 51, 136-142. doi: 10.1111/j.1469-8749.2008.03118.x

Christian, P., Lee, S. E., Donahue Angel, M., Adair, L. S., Arifeen, S. E., Ashorn, P., et al. (2013). Risk of childhood undernutrition related to small-for-gestational age and preterm birth in low- and middle-income countries. Int. J. Epidemiol. 42, 1340-1355. doi: 10.1093/ije/dyt109

Colditz, P., Greisen, G., and Pryds, O. (1988). Comparison of electrical impedance and 133xenon clearance for the assessment of cerebral blood flow in the newborn infant. Pediatr. Res. 24, 461-464. doi: 10.1203/00006450-19881000000008

Dani, K. A., Thomas, R. G., Chappell, F. M., Shuler, K., Muir, K. W., and Wardlaw, J. M. (2012). Systematic review of perfusion imaging with computed tomography and magnetic resonance in acute ischemic stroke: heterogeneity of acquisition and postprocessing parameters: a translational medicine research collaboration multicentre acute stroke imaging study. Stroke 43, 563-566. doi: 10.1161/STROKEAHA.111.629923

De Vis, J. B., Petersen, E. T., Alderliesten, T., Groenendaal, F., de Vries, L. S., van Bel, F., et al. (2014). Non-invasive MRI measurements of venous oxygenation, oxygen extraction fraction and oxygen consumption in neonates. NeuroImage 95, 185-192. doi: 10.1016/j.neuroimage.2014. 03.060

Estourgie-van Burk, G. F., Bartels, M., Hoekstra, R. A., Polderman, T. J., Delemarre-van de Waal, H. A., and Boomsma, D. I. (2009). A twin study of cognitive costs of low birth weight and catch-up growth. J. Pediatr. 154, 29-32. doi: $10.1016 /$ j.jpeds.2008.07.016

Grome, J. J., and McCulloch, J. (1981). The effects of chloral hydrate anesthesia on the metabolic response in the substantia nigra to apomorphine. Brain Res. 214, 223-228. doi: 10.1016/0006-8993(81)90460- 1

Hashem, M., Zhang, Q., Wu, Y., Johnson, T. W., and Dunn, J. F. (2020). Using a multimodal near-infrared spectroscopy and MRI to quantify gray matter metabolic rate for oxygen: a hypothermia validation study. NeuroImage 206:116315. doi: 10.1016/j.neuroimage.2019. 11631

Herscovitch, P., Mintun, M. A., and Raichle, M. E. (1985). Brain oxygen utilization measured with oxygen-15 radiotracers and positron emission tomography: generation of metabolic images. J. Nuclear Med. 26, 416-417.

Kusaka, T., Isobe, K., Yasuda, S., Koyano, K., Nakamura, S., Nakamura, M., et al. (2014). Evaluation of cerebral circulation and oxygen metabolism in infants using near-infrared light. Brain Dev. 36, 277-283. doi: 10.1016/j.braindev.2013. 05.011

Laptook, A. R., O'Shea, T. M., Shankaran, S., Bhaskar, B., and Network, N. N. (2005). Adverse neurodevelopmental outcomes among extremely low birth weight infants with a normal head ultrasound: prevalence and antecedents. Pediatrics 115, 673-680. doi: 10.1542/peds.20040667

Liu, P., Chalak, L. F., Krishnamurthy, L. C., Mir, I., Peng, S. L., Huang, H., et al. (2016). T1 and T2 values of human neonatal blood at 3 tesla: dependence on hematocrit, oxygenation, and temperature. Magn. Reson. Med. 75, 1730-1735. doi: $10.1002 / \mathrm{mrm} .25775$

Liu, P., Huang, H., Rollins, N., Chalak, L. F., Jeon, T., Halovanic, C., et al. (2014). Quantitative assessment of global cerebral metabolic rate of oxygen (CMRO2) in neonates using MRI. NMR Biomed. 27, 332-340. doi: 10.1002/nbm. 3067

Liu, P., Xu, F., and Lu, H. (2013). Test-retest reproducibility of a rapid method to measure brain oxygen metabolism. Magn. Reson. Med. 69, 675-681. doi: $10.1002 / \mathrm{mrm} .24295$

Martinussen, M., Fischl, B., Larsson, H. B., Skranes, J., Kulseng, S., Vangberg, T. R., et al. (2005). Cerebral cortex thickness in 15-year-old adolescents with low birth weight measured by an automated MRI-based method. Brain 128, 2588-2596. doi: 10.1093/brain/awh610

McLachlan, P. J., Kishimoto, J., Diop, M., Milej, D., Lee, D. S. C., de Ribaupierre, S., et al. (2017). Investigating the effects of cerebrospinal fluid removal on cerebral blood flow and oxidative metabolism in infants with posthemorrhagic ventricular dilatation. Pediatr. Res. 82, 634-641. doi: 10.1038/pr.20 17.131

Munro, M. J., Walker, A. M., and Barfield, C. P. (2004). Hypotensive extremely low birth weight infants have reduced cerebral blood flow. Pediatrics 114, 1591-1596. doi: 10.1542/peds.2004-1073

Odell, C. D., Kotelchuck, M., Chetty, V. K., Fowler, J., Stubblefield, P. G., Orejuela, M., et al. (2006). Maternal hypertension as a risk factor for low birth weight infants: comparison of haitian and african-american women. Maternal Child Health J. 10, 39-46. doi: 10.1007/s10995-0050026-2

Peng, S. L., Dumas, J. A., Park, D. C., Liu, P., Filbey, F. M., McAdams, C. J., et al. (2014). Age-related increase of resting metabolic rate in the human brain. NeuroImage 98, 176-183. doi: 10.1016/j.neuroimage.2014 04.078

Qi, Y., Liu, P., Lin, Z., Lu, H., and Wang, X. (2018). Hemodynamic and metabolic assessment of neonates with punctate white matter lesions using phase-contrast MRI and T2-relaxation-under-spin-tagging (TRUST) MRI. Front. Physiol. 9:233. doi: 10.3389/fphys.2018.00233

Shetty, A. N., Lucke, A. M., Liu, P., Sanz Cortes, M., Hagan, J. L., Chu, Z. D., et al. (2019). Cerebral oxygen metabolism during and after therapeutic hypothermia in neonatal hypoxic-ischemic encephalopathy: a feasibility study using magnetic resonance imaging. Pediatr. Radiol. 49, 224-233. doi: 10.1007/ s00247-018-4283-9

Silva, I. B. D., Cunha, P., Linhares, M. B. M., Martinez, F. E., and Camelo Junior, J. S. (2018). Neurobehavior of preterm, small and appropriate for gestational age newborn infants. Revista paulista de pediatria 36, 407-414. doi: 10.1590/1984$0462 / ; 2018$

Skranes, J., Vangberg, T. R., Kulseng, S., Indredavik, M. S., Evensen, K. A., Martinussen, M., et al. (2007). Clinical findings and white matter abnormalities seen on diffusion tensor imaging in adolescents with very low birth weight. Brain 130, 654-666. doi: 10.1093/brain/awm001

Tchamo, M. E., Prista, A., and Leandro, C. G. (2016). Low birth weight, very low birth weight and extremely low birth weight in African children aged between 0 and 5 years old: a systematic review. J. Dev. Origins Health Dis. 7, 408-415. doi: $10.1017 / S 2040174416000131$

Tortora, D., Lo Russo, F. M., Severino, M., Parodi, A., Massirio, P., Ramenghi, L. A., et al. (2020). Regional impairment of cortical and deep gray matter perfusion in preterm neonates with low-grade germinal matrix-intraventricular hemorrhage: an ASL study. Neuroradiology 62, 1689-1699. doi: 10.1007/ s00234-020-02514-9

Uematsu, M., Takasawa, M., Hosoi, R., and Inoue, O. (2009). Uncoupling of flow and metabolism by chloral hydrate: a rat in vivo autoradiographic study. Neuroreport 20, 219-222. doi: 10.1097/WNR.0b013e32830 2ee46

Wintermark, P., Hansen, A., Warfield, S. K., Dukhovny, D., and Soul, J. S. (2014). Near-infrared spectroscopy versus magnetic resonance imaging to study brain perfusion in newborns with hypoxic-ischemic encephalopathy treated 
with hypothermia. NeuroImage 85, 287-293. doi: 10.1016/j.neuroimage.2013. 04.072

Woodward, L. J., Anderson, P. J., Austin, N. C., Howard, K., and Inder, T. E. (2006). Neonatal MRI to predict neurodevelopmental outcomes in preterm infants. N. Engl. J. Med. 2006, 685-694. doi: 10.1056/NEJMoa053792

Wright, E. A., d'Esterre, C. D., Morrison, L. B., Cockburn, N., Kovacs, M., and Lee, T. Y. (2016). Absolute cerebral blood flow infarction threshold for 3-hour ischemia time determined with CT perfusion and 18F-FFMZ-PET imaging in a porcine model of cerebral ischemia. PloS one 11:e158157. doi: 10.1371/journal. pone. 0158157
Conflict of Interest: The authors declare that the research was conducted in the absence of any commercial or financial relationships that could be construed as a potential conflict of interest.

Copyright (C) 2021 Qi and He. This is an open-access article distributed under the terms of the Creative Commons Attribution License (CC BY). The use, distribution or reproduction in other forums is permitted, provided the original author(s) and the copyright owner(s) are credited and that the original publication in this journal is cited, in accordance with accepted academic practice. No use, distribution or reproduction is permitted which does not comply with these terms. 